\title{
A COMUNICAÇÃO NAS ORGANIZAÇÕES: O DISCURSO QUE SALVA EM MOMENTOS DE CRISE
}




\section{A COMUNICAÇÃO NAS ORGANIZAÇÕES: O DISCURSO QUE SALVA EM MOMENTOS DE CRISE}

Resumo: O presente trabalho propõe analisar a necessidade da implantação de um sistema de comunicação para as empresas, a fim de criar condições para consolidação de sua reputação por meio de estratégias criadas a partir de ferramentas do campo da assessoria de comunicação. No que tange ao procedimento metodológico do estudo, vale destacar que o mesmo está referendado numa revisão bibliográfica capaz de criar subsídios na contemplação dos seguintes temas: comunicação organizacional, comunicação integrada e gerenciamento de crises. Palavras chave: Comunicação Organizacional; Gerenciamento de Crise; Imagem; Comunicação Integrada

\section{LA COMUNICACIÓN EN LAS ORGANIZACIONES: EL DISCURSO QUE AHORRA EN TIEMPOS DE CRISIS}

Resumen: Este estudio tiene como objetivo analizar la necesidad de la implementación de un sistema de comunicación para las empresas a fin de crear las condiciones para la consolidación de su reputación por medio de estrategias creadas por las herramientas del campo de la consultoría de comunicación. Cuanto al enfoque metodológico, cabe destacar que lo mismo está respaldado por una bibliografía capaz de crear subsidios en la contemplación de los siguientes temas: la comunicación organizacional comunicación, integrada y gestión de crisis. Palabras clave: Comunicación Organizacional; Crisis Management; Imagen; Comunicación Integrada

THE COMMUNICATION IN ORGANIZATIONS: THE SPEECH THAT SAVES IN CRISIS MOMENTS

Abstract: This study aims to analyze the need of the implementation of a communication system for companies in order to create conditions for consolidating its reputation through strategies created from tools of the field of communications consultancy. Regarding the methodological approach of the study, it is noteworthy that the same is countersigned on a literature review able to create subsidies in contemplation of the following topics: organizational communication, integrated communication and crisis management.

Keywords: Organizational Communication; Crisis Management; Image; Integrated Communication 


\section{INTRODUÇÃO}

A comunicação nas organizações, ou comunicação organizacional', integra as Ciências Sociais Aplicadas, apresentando ligação com as teorias das organizações, as organizações em geral e as teorias da comunicação. Dessa forma, essa conexão a coloca em um patamar estratégico no segmento dos negócios, o qual está em constante mudança, principalmente a partir de meados do século XX, afetado, sobretudo, pelo processo acelerado de globalização.

A respeito de tal fenômeno, Ilana Polistchuk e Aluizio Trinta (2003) comentam que o determinismo tecnológico, abordado pelo teórico Marshall McLuhan em seus estudos midiológicos durante as décadas de 1960 e 1970, instituiu novos hábitos de percepção, fazendo com que toda tecnologia aplicada à comunicação contribuísse decisivamente para a configuração social. "A invenção e a adoção de uma ou outra tecnologia de comunicação traz consigo transformações sociais, culturais, políticas e de civilização.” (p. 135). Essa abordagem impactou as diversas organizações, particularmente após a década de 1990, quando o mundo, já interligado por conhecimentos compartilhados, passou a se comportar, de fato, como uma "aldeia global".

De acordo com Paul Argenti (2006), a diferença do ambiente de negócios há 40 ou 50 anos em relação aos dias atuais se dá principalmente pelo desenvolvimento dos meios de comunicação, os quais ele classifica como importantes canais para expressão e debate de questões empresariais. Em seus estudos, o autor salienta que as lideranças empresariais atuais devem preparar-se para o assédio da mídia - e também de grupos específicos de reivindicação que possam valer-se da mesma, comprometendo a reputação e os resultados de suas empresas -, devido ao aumento da influência das grandes corporações ${ }^{2}$, refletindo no maior interesse em relação aos impactos gerados em níveis ambien-

1 O termo "comunicação organizacional” é usado, no Brasil, indistintamente dos termos "comunicação empresarial" e "comunicação corporativa", que designam todas as atividades de comunicação realizadas pelas organizações em geral. No entanto, neste trabalho, será utilizada a terminologia “comunicação organizacional”, com base em Kunsch (2003), que a define como um termo aglutinador de todas as ações organizacionais, apresentando maior amplitude e aplicando-se a qualquer tipo de organização - pública, privada, sem fins lucrativos, ONGs (organizações não-governamentais) -, associações, sindicatos, clubes etc.

2 De acordo com Argenti (2006), das 100 principais economias do mundo, 51 são empresas multinacionais e as 49 restantes são países. 
tal, social, econômico e político. "Em termos gerais, o público está procurando empresas que demonstrem cuidado com as comunidades em que atuam, dos pontos de vista ambiental e humano." (ARGENTI, 2006, p. 8).

Como exemplo, é possível citar a atuação da revista canadense Adbusters, dedicada a ridicularizar grandes corporações e também os governos, através da chamada cultura jamming, que, em linhas gerais, designa uma manifestação contra-hegemônica.

Colar uma imagem de Charles Mason sobre um outdoor de calça jeans da Levis, jogar tortas em Bill Gates e despejar sacos de lixo cheios de sapatos nos arredores de Nike Town para protestar contra o uso de mão-de-obra infantil no Paquistão - na fabricação de bolas de futebol Nike por seis centavos a hora - são algumas das táticas rotineiras que os ativistas têm para fazer suas declarações antiempresariais chegarem ao público. (ARGENTI, 2006, p. 10).

Ironicamente, no entanto, os avanços tecnológicos que beneficiaram o ativismo antiempresarial também auxiliaram campanhas coordenadas pelas empresas, a fim de evitar que notícias negativas sobre elas chegassem ao público. Essa ideia é corroborada por Nassar (2009), que afirma que a ação da comunicação organizacional deve ser pensada de forma estratégica e proativa, visando à eficácia dos processos da companhia com os distintos stakeholders (públicos de interesse), a fim de mitigar impactos em diversos âmbitos. "A partir desse posicionamento em relação à procura de resultados é que nascem as ideias atuais de qualidade, respeito ao consumidor e ao cidadão, sustentabilidade, responsabilidade social e histórica." (NASSAR, 2009, p. 63).

Neste sentido, a comunicação insere-se como eixo norteador da interação com os diversos públicos, verificando demandas existentes e atuando como elemento crucial para a sobrevivência da organização. De acordo com Ângela Lovato Dellazzana (2005, P.26), é através da comunicação que são estabelecidos os diálogos a respeito das políticas, da cultura organizacional, das pretensões sobre o futuro da empresa, entre outros, sendo tais informações fundamentais, "pois os indivíduos que possuem conhecimento podem responder apropriadamente às diversas tarefas, problemas e ações da organização."

Complementando as ideias da autora, Nassar (2009) aponta que a comunicação organizacional é responsável ainda por avaliar e reconhecer as demandas dos seus receptores, legitimando as suas relações, além de também servir 
na melhoria do ambiente de trabalho, ou seja, seu campo de atuação ocorre nos patamares exógenos e endógenos.

Assim, percebe-se que a comunicação deve ser diretamente ligada à estratégia geral de quaisquer organizações, implicando na adequação das mensagens para cada tipo de público, levando-se em consideração os canais e as análises das respostas para determinar se o objetivo foi bem-sucedido. Ao desenvolver, portanto, tal estratégia, as empresas precisam aliar missão, visão e valores aos esforços de comunicação, possibilitando um sistema sinérgico e eficaz, no qual "as informações e conhecimentos circulem por todas as unidades da organização, dando suporte ao desenvolvimento das atividades organizacionais e ao processo decisório." (ANGELONI, 2010, p. 57).

Em consonância com essa abordagem, Argenti (2006, p. 43) comenta que a criação de uma estratégia de comunicação envolve quatro variáveis: "definir a estratégia geral da empresa para a comunicação, analisar os públicos-alvos relevantes e transmitir bem as mensagens. Além disso, é preciso analisar as respostas [...] para determinar se a comunicação foi bem sucedida".

Dessa forma, o papel que as ações comunicativas assumiram no meio corporativo atual deixou, então, de ser considerado algo periférico e suas estratégias devem ser convertidas em um processo contínuo de melhoria. "Buscar uma comunicação excelente deve constituir uma meta a ser alcançada pelos que a dirigem no cotidiano das organizações. A comunicação excelente é aquela que se baseia em conhecimentos [...] e valoriza a cultura corporativa [...]." (KUNSCH, 2009, p. 117).

Como ilustração deste movimento, que passou de um panorama irrelevante da comunicação nas organizações para uma função primordial, podese mencionar o contexto histórico do final do século XIX, quando as relações produtivas nas organizações pautavam-se na racionalização controlada do trabalho, a partir das abordagens do engenheiro americano Frederick Taylor, que objetivavam aumentar o lucro e inibir as conquistas da classe operária. De acordo com Chaparro (2010, p. 5), com o taylorismo, "a máscara do conhecimento científico passou a encobrir o verdadeiro objetivo patronal, num quadro de luta de classe marcado pela violência." O autor ressalta que a visão que se tinha da importância da comunicação se resumia ao lema proclamado por um dos mais conhecidos industriais americanos da época, William Henry Valderbilt: "the public be dammed", ou "o público que se dane".

No contexto atual, todavia, pautado por novas tendências de mercado, 
possibilidades tecnológicas e conquistas legais do cidadão, acabou por criar uma lógica de competição ancorada no compartilhamento das informações. "No cenário novo da informação, a instantaneidade e a abrangência ilimitada da difusão eliminaram o intervalo de tempo entre o momento da materialização dos fatos e sua divulgação em forma de notícia." (CHAPARRO, 2010, p. 19).

Assim, acaba-se por deparar com um novo sistema comunicativo, no qual distintos tipos de mídias deslocam a perspectiva das formas tradicionais - baseadas em um processo indireto, público e unilateral -, invertendo o processo de produção e consumo das informações. As "novas mídias", como são chamadas por Dizard Jr., fornecem serviços especializados a vários segmentos de público e dão "a todos a oportunidade de falar assim como de escutar. Muitos falam com muitos - e muitos respondem de volta." (2000, p. 23). Desta maneira, novas modalidades de coletar, armazenar e transmitir informações estão sendo (re)criadas por estas novas formas de comunicar, com um objetivo claro e preciso: a maximização do lucro.

Trasladando essa ideia para o campo das organizações, nota-se que a comunicação também precisa avançar por meio de formas e funções específicas de orientação para atender às suas necessidades. Sobre as primeiras, Torquato (2002) destaca que a os processos comunicativos assumem quatro modalidades distintas dentro da organização: a primeira é a vertente cultural, em que se inserem os costumes, perfis individuais, valores da comunidade e as ideias (é, portanto, o clima interno da organização); a segunda dimensão é a comunicação administrativa, que engloba os memorandos, correspondências internas e outros materiais; a terceira forma é a comunicação social, que envolve, por exemplo, o jornalismo, relações públicas, publicidade, editoração e marketing; a última modalidade citada pelo autor é conhecida como sistema de informação, que agrega os bancos de dados de determinada organização.

Em relação às funções, Argenti (2006) aborda os seguintes aspectos relativos à comunicação organizacional: 1) gerenciamento de reputação; 2) propaganda corporativa; 3) relações com a mídia; 4) comunicação de marketing; 5) comunicação interna; 6) relações com os investidores; 7) responsabilidade social corporativa; 8) relações com o governo; 9) e gerenciamento de crise.

Nesse ínterim, pode-se afirmar que a comunicação nas organizações deve ser pensada a partir de uma concepção integrada, capaz de contemplar a complexidade do fenômeno comunicacional inerente à natureza das organizações e suas conexões junto aos diferentes públicos, além de sua função estratégica e instrumental no ambiente de negócios contemporâneo. 


\section{A COMUNiCAÇÃo INTEGRAdA E A CONSTRUÇÃO DA IMAGEM, IDENTIDADE E REPUTAÇÃO}

Conforme tratado na seção anterior, uma das formas mais efetivas de alcançar os resultados esperados no ambiente dos negócios ancora-se na comunicação e sua atuação deixa de ter uma função meramente tática, passando a ser considerada estratégica. A partir daí, surge o conceito da Comunicação Integrada, que, como afirma Kunsch (2009, p. 113), advém da necessidade de contemplar uma visão sistêmica e abrangente dos processos comunicativos nas e das organizações, "considerando todos aqueles aspectos relacionados com a complexidade do fenômeno comunicacional inerente à natureza das organizações, bem como os relacionamentos interpessoais, a dimensão da comunicação humana, além da função estratégica e instrumental."

Tal abordagem, segundo a autora, direciona a convergência das diversas áreas da comunicação em uma ação sinérgica, formando um mix, um composto de ações que compreende os aspectos administrativos, internos, institucionais e mercadológicos.

Na verdade, o que defendo é a adoção, por parte das organizações, de uma filosofia da comunicação integrada e da não-fragmentação dessa comunicação [... ] Ou seja (sic) deve haver total integração entre a Comunicação Interna, a Comunicação Institucional e a Comunicação Mercadológica para a busca e o alcance da eficácia, da eficiência e da efetividade organizacional, em benefício dos públicos e da sociedade como um todo e não só da organização separadamente. (KUNSCH, 2009, p. 114-115).

Já para Bueno (2005), o termo diz respeito à articulação das atividades de comunicação aos processos de gestão, planejamento e marketing, obedecendo a uma política de diretrizes comuns. Desta forma, pode-se entender que a comunicação integrada busca modular as diversas mensagens das organizações aos distintos públicos, levando-se em consideração a coerência de sua identidade e da imagem do que a mesma é, busca, e parece ser.

Identidade, segundo Torquato (2008), diz respeito às características relacionadas aos aspectos físicos da empresa, formando sua personalidade e composição. Ou seja, a identidade "define os limites, os contornos e as possibilidades do posicionamento da marca." (TORQUATO, 2008, p. 104). Em consonância com esta ideia, Argenti (2006) afirma que a identidade de uma organização 
representa sua consolidação visual, sendo transmitida através do "nome, logomarca, lema, produtos, serviços, instalações, folheteria, uniformes e todas as outras peças que possam ser exibidas, criadas pela organização e comunicadas a uma grande variedade de públicos." (ARGENTI, 2006, p. 80-81).

Imagem, todavia, caracteriza-se como o reflexo da identidade de determinada organização sob o ponto de vista de seus stakeholders, podendo variar de acordo com cada público. (TORQUATO, 2008). Então, dependendo do público envolvido, a organização pode transmitir diferentes imagens, criando percepções que, para Argenti (2006, p. 96), estão baseadas nas leituras e informações prévias a respeito da organização, além dos símbolos visuais que são reconhecíveis. "Mesmo que você nunca tenha comido um hambúrguer no McDonald's, terá certas percepções sobre a empresa e seus produtos."

De acordo com o autor, a reputação é o somatório de ambos os conceitos, sendo construído ao longo do tempo, independentemente de percepções isoladas em um determinado período. "Uma reputação sólida é criada quando a identidade de uma organização e sua imagem estão alinhadas. [...] Como resultado, a intangível entidade da reputação é, sem dúvida, uma fonte de vantagem competitiva." (ARGENTI, 2006, p. 97-98).

Como ilustração da importância da reputação no ambiente de negócios, o autor aponta o aumento do interesse dos executivos nas pesquisas e nos rankings de diversas revistas especializadas, que procuram divulgar a lista das mais admiradas e melhores empresas nos diversos setores da economia.

Entre 1999 e 2000, o número de CEOs que responderam à pesquisa Avaliação de Reputação Corporativa, feita pela Hill \& Knowlton para a revista Chief Executive, saltou de 19 para 37\%. Em resposta a essa demanda, muitas empresas de relações públicas e consultoria passaram a oferecer medição de reputação e serviços de gerenciamento para seus clientes corporativos. (ARGENTI, 2006, p. 98).

Sobre os trabalhos de gerenciamento da reputação, Argenti (2006) afirma que devem ser estabelecidos de forma a descobrir e preservar as percepções dos públicos em relação às organizações, alinhando-as às suas visões e valores. “Uma reputação bem estabelecida, por sua vez, converte-se em orgulho e compromisso - entre os funcionários, consumidores e o público em geral -, e essas qualidades são ativos insubstituíveis em um ambiente de negócios cada vez mais competitivo em escala global." (ARGENTI, 2006, p. 103). Trata-se, portanto, de 
um importante instrumento para a sobrevivência da instituição em períodos de instabilidade financeira, política, ambiental ou social, ligados diretamente a uma das funções da comunicação organizacional: o gerenciamento de crises.

\section{O GERENCIAMENTO DE CRISES NAS ORGANIZAÇÕES E O PAPEL DA COMUNICAÇÃO}

A comunicação em situações de crise possui direcionamentos pautados na padronização dos diversos processos das organizações para que se tenham disponíveis planos claros e objetivos para os casos inesperados e indesejados. De acordo com Rosa (2008), as crises são combatidas sob o ponto de vista da repercussão. Em suas possíveis dimensões, o reflexo vai depender da forma como se administra a política de comunicação durante o evento, tendo como objetivo central conter o desgaste para a imagem da companhia. Corroborando esta ideia, Neves (2000) revela que, nas crises, há sempre uma superexposição da empresa, implicando em prejuízos dos mais variados tipos, seja no aspecto da credibilidade, como do ponto de vista econômico. No entanto, com o posicionamento correto, é possível mitigá-los e consolidar ainda mais a empresa no mercado.

Rosa (2008) ainda explica que nos momentos de normalidade é que devem ser pensadas as medidas preventivas para lidar com as dificuldades antes que as mesmas aconteçam. "Resumindo: hora de crise é hora de reagir - e não de planejar. Planejamento se faz em tempos de normalidade. E quanto melhor for, melhor será a resposta quando a rotina for quebrada." (ROSA, 2008, p. 70). A palavra-chave do gerenciamento de crises é, portanto, planejamento.

Um Plano de Gerenciamento de Crises, sob a ótica da comunicação, é um conjunto de medidas, posturas e consensos capazes de fazer com que o sucesso de uma ação no lugar onde ocorreu uma situação adversa possa ser captado como tal. [...] A imagem transmitida por uma organização ou um líder numa situação de crise é tão ou mais importante do que suas ações. Ou seja, o importante não é apenas o que você faz, mas principalmente como você faz. (ROSA, 2008, p. 71).

Neste momento, pode-se valer das considerações de Granado (2004) a respeito da política de Comunicação Institucional da Petrobras (válidas para todas as empresas do grupo), que está baseada, segundo o autor, em cinco pontos: "não subestimar uma crise; eventos menores podem ter grande repercussão; 
agilidade de informação; precisão da informação e credibilidade e a fonte de informação deve ser a companhia" (GRANADO, 2004, p. 31). Estas diretrizes foram elaboradas a partir de experiências com o vazamento de óleo na Baía de Guanabara em 2000 e o afundamento da plataforma de exploração P-36 na Bacia de Campos, em 2001.

O risco de alguma operação redundar em Crise é constante para a Petrobras, [... em função do gigantismo da companhia, que possui treze refinarias no País e dutos com mais de 16 mil quilômetros, que transportam milhões de litros de combustível e derivados todos os dias. Essa constatação obrigou a empresa a ter um Sistema de Comunicação para Situações de Crise, para evitar situações que comprometessem a credibilidade e a imagem da companhia por causa de falhas nos procedimentos de comunicação. (GRANADO, 2004, p. 31).

Para o autor, a agilidade e a clareza são requisitos fundamentais para que as informações satisfaçam a todos os grupos de relacionamento da companhia, como investidores, imprensa, parceiros, grandes clientes e empregados. "Normalmente, quando acontece um vazamento, todos querem saber quanto vazou. Se não há essa informação, a companhia não divulga. É preciso ter segurança, precisão na informação para que haja credibilidade." (GRANADO, 2004, p. 32-33).

Logo, o grande desafio do gerenciamento em momentos de crise é fazer com que a percepção de diversas ações seja a mais positiva possível. Para isso, Rosa (2008) sugere um plano de gerenciamento de crises capaz de atingir tal objetivo, com os seguintes pontos: 1) Avaliação das crises mais prováveis, que, para o autor, pode ser de natureza econômica, humana, natural, legal etc; 2) Criação de um comando nas situações de crise, com as definições de quais líderes irão enfrentar o processo; 3) Elaboração de uma doutrina da crise, que tem como base definir a forma como a organização irá se comportar em cada situação; 4) Criação de uma base de dados capaz de munir o porta-voz de informações de todos os tipos, otimizando o tempo de resposta; 5) Definição do porta-voz para exposição na mídia; 6) Implementação de auditorias permanentes, com o objetivo de descobrir potenciais focos de crises.

Como exemplo, acerca dos procedimentos a serem adotados nos momentos de crise, a revista Exame publicou, na edição de 2 de novembro de 2011, o caso da contaminação do Toddynho, da Pepsico, por uma mistura de detergente e soda cáustica envasada por engano. O incidente, ocorrido em setembro de 2011, cau- 
sou a queima de boca e garganta de pelo menos 39 clientes, deflagrando uma das piores crises da história da empresa. No entanto, a Pepsico demorou dois dias para se posicionar sobre o problema. De acordo com os especialistas, "em momentos como esse, dois dias podem ser uma eternidade, sobretudo em tempos de consumidores conectados por redes sociais virtuais." (ONAGA, 2011, p. 102).

Dias depois da primeira reunião do comitê de crise da Pepsico, a empresa veiculou um anúncio em redes de TV gaúchas informando o problema, sem explicar em detalhes as causas, e pedindo desculpas aos consumidores. Àquela altura, porém a contaminação do Toddynho já era assunto nacional. Logo depois das primeiras denúncias, surgiram reportagens em jornais, programas de rádio e de TV. Rapidamente, o fato tomou conta de redes como o Twitter e o Facebook. (ONAGA, 2011, p. 102-104).

Na matéria, foi publicada ainda uma espécie de cartilha para proteger a imagem das empresas em situações de problema, elaborada pela consultoria Crisis Solution. De acordo com os consultores, a agilidade e transparência também são qualidades fundamentais para blindar a imagem e reputação em casos de crise. Deve-se reconhecer rapidamente que há um problema e posicionar-se como parte da solução; emitir um comunicado em um prazo de até quatro horas depois da ocorrência; assumir a posição de referência sobre o assunto com informações precisas; ter porta-vozes bem treinados e preparados para agir a qualquer momento; e buscar soluções eficazes que atendam às expectativas da opinião pública.

Sobre o que não se deve fazer, os analistas alertam sobre os possíveis prejuízos decorrentes do posicionamento de esperar até que o assunto desapareça de forma espontânea; também orientam para não subestimar o problema em declarações públicas; não desqualificar a suposta vítima sem provas contundentes; não tentar desacreditar autoridades e especialistas; e não ter um comportamento arrogante no discurso e no tratamento do problema.

Com base no exposto, pode-se perceber que, no atual ambiente de negócios, a mídia ganhou novas possibilidades, eliminando o tempo e a retenção de informações por parte de determinadas fontes. Esses fatores impuseram às empresas a necessidade de uma resposta mais eficiente e rápida a todos os seus públicos. No próximo momento, será mostrado qual o papel da assessoria de imprensa e o treinamento de porta-vozes neste processo, estabelecendo para a empresa um nexo entre as redações e a sociedade, capaz de atender às demandas e fornecer informações adaptadas aos interesses dos veículos de 
comunicação e da própria organização. Como assinala Chaparro (2012, p. 3), "nesse mundo novo, as instituições, incluindo-se as empresas, agem pelo que dizem, em especial pelos acontecimentos significantes que produzem, com os quais interferem na realidade, ao usarem a eficácia difusora do jornalismo."

\section{CONSIDERAÇÕES FINAIS}

Chega-se ao final deste trabalho com o intuito de não apenas tecer algumas considerações que sejam pertinentes, mas também demonstrar outros elementos de importância, como, por exemplo, o alcance dos objetivos inicialmente propostos e a resposta aos problemas encontrados no decorrer da pesquisa.

Ligando tais preceitos ao objeto de estudo, pode-se dizer que a comunicação nas organizações é ferramenta estratégica. Com relação aos objetivos inicialmente propostos, pode-se considerar que todos foram alcançados com êxito. Tendo como objetivo geral a análise da necessidade de implantação de um sistema eficaz de comunicação para mitigar prejuízos de imagem e reputação organizacional, é traçada, no decorrer do trabalho, uma discussão que revela seu papel estratégico na redução de possíveis ruídos no processo de comunicação em demandas que envolvam a mídia.

Enfim, pretendeu-se demonstrar a forma positiva sob a qual a comunicação organizacional pode servir na melhoria dos processos com os diversos stakeholders, constituindo-se como um diferencial no gerenciamento de crise aplicado aos diversos contextos.

\section{REFERÊNCIAS}

ANGELONI, Maria Terezinha. Comunicação nas organizações da era do conhecimento. São Paulo, Atlas, 2010.

ARGENTI. Paul. Comunicação empresarial. Tradução Adriana Rieche. Rio de Janeiro: Elsevier, 2006.

BUENO, Wilson da Costa. Comunicação empresarial no Brasil: uma leitura crítica. São Paulo: All Print, 2005.

. Comunicação e interatividade: a comunicação empresarial se prepara para enfrentar os desafios do século XXI. Amparo: Comtexto Comunicação e Pesquisa/ Unimed Amparo, 1995.

CHAPARRO, Manuel Carlos. Cem Anos de Assessoria de Imprensa. In: DUARTE, Jorge (Org.). Assessoria de imprensa e relacionamento com a mídia: teoria e prática. 2. ed. São Paulo: Atlas, 2010. p. 3-21. 
DELLAZZANA, Ângela Lovato. Comunicação organizacional: uma visão complexa do discurso das organizações. Porto Alegre: Pontifícia Universidade Católica do Rio Grande do Sul, 2005

GRANADO, Erasmo. Gerenciamento de crises no âmbito empresarial. In: IV ENCONTRO DE ESTUDOS: Gerenciamento de Crises: Modelos e Inovação. Brasília: Gabinete de Segurança Institucional; Secretaria de Acompanhamento e Estudos Institucionais, 2004.

KUNSCH. Margarida Maria Krohling (Org.). Gestão estratégica em comunicação organizacional e relações públicas. 2. ed. São Caetano do Sul, SP: Difusão Editora, 2009.

NASSAR, Paulo. Conceitos e processos de comunicação organizacional. In: KUNSCH. Margarida Maria Krohling (Org.). Gestão estratégica em comunicação organizacional e relações públicas. 2. ed. São Caetano do Sul, SP: Difusão Editora, 2009. p. 61-75.

NEVES, Roberto de Castro Neves. Comunicação empresarial integrada: como gerenciar: imagem, questões públicas, comunicação simbólica, crises empresariais. 3. ed. Rio de Janeiro: Mauad, 2000.

ONAGA, Marcelo. A dúvida cruel. Exame, São Paulo, SP, ano 45, n. 1003, p. 102-106, 2 nov. 2011.

ROSA, Mário. A era do escândalo: lições, relatos e bastidores de quem viveu as grandes crises de imagem. 5. ed. São Paulo: Geração Editorial, 2008.

TORQUATO, Gaudêncio. Tratado de comunicação organizacional e política. São Paulo: Cengage Learning, 2008.

RECEBIDO EM: 03/09/2012

ACEITO PARA PUBLICAÇÃO: 25/10/2012

\section{Leila Arruda Pinto}

Graduada em Comunicação Social com habilitação em Jornalismo pela Faculdade do Sul - Unime Itabuna. Analista de Comunicação e Marketing na Unime Itabuna.

\section{Rodrigo Muniz Ferreira Nogueira}

Mestre em Cultura e Turismo pela Universidade Estadual de Santa Cruz. Coordenador e professor do curso de Comunicação Social com habilitação em Jornalismo da Unime Itabuna. 